\title{
Some Remarks on the Environmental Determinants: Factors Affecting the Quality of Urban Life
}

\author{
Gündüz ATALIK*
}

\begin{abstract}
Actually, a number of arguments arising from the actual experience of performance as a whole in developed areas and indications of cross-cultural differentiation in developing areas prove that there are certain limitations in implementing environmental policies and international commitments aimed at steering a course towards sustainable futures for European regions. Since the choice of a particular method for a specific project assessment depends on the cultural context, in addition to the political and administrative structures, public participation becomes fundamental in playing more effective roles in environmental decision procedures in European regions.

In fact, among the number of approaches in human geography, positivist and humanistic approaches used together seem particularly meaningful in respect to regional differentiation in efforts leading to ecologically sustainable development. From the viewpoint of ecology, location and public participation, in other words for a bottom-up approach to European integration through international cooperation, the human eco-centric view seems the most appropriate viewpoint, since it is based on the human relationships and place dependencies. However, without explicit environmental premises, the sustainability debate seems indeterminate.

Just as, certain findings verify the hypothesis that the community perception of urban health risks is key to understanding how a community perceives health risks, so is it recognized that not take into account the responding behavioural reactions to urban health risks for the affected community results in a failure to obtain objective measures of risk to design urban and regional environment projects.

Specifically, from the standpoint of an ecologically sustainable development, it may be useful to examine the satisfaction rates of people in certain urban areas by utilizing selected models in order to evaluate likely planning decisions. In this paper, the performance of the Istanbul metropolitan area is examined by using a number of independent variables covering housing conditions, accessibility conditions, social and cultural parameters and environmental impact as a whole, besides also utilizing some European experience in this field.
\end{abstract}

JEL Classification: R10, Q56, C31

Keywords: Epistemological Differentiation in Environmental Performance, Interregionality in Sustainable Development, Community Perception, Objective and Subjective Indicators, Satisfaction Rate for Quality of Urban Life

\section{Introduction}

In dealing with recent experience and literature in the framework of sustainable development, it will be worthwhile to consider the relevancy and utility of some approaches in

\footnotetext{
* Department of Urban and Regional Planning, Istanbul Technical University, Taskisla, Taksim 34347 Istanbul, Turkey

E-mail : atalik@itu.edu.tr
} 
Philosophy of Science, particularly in evaluating transboundary determinants of ecologically sustainable development. It is known that, when the epistemology for positivist approaches requires some experience be firmly established as verifiable evidence on which all will agree on the one hand, the epistemology for humanistic approaches requires some knowledge obtained subjectively in a world of meanings created by individuals emphasizing individuality and subjectivity rather than replicability and truth. A simple evaluation of these approaches together could give us a simple understanding for the determinants of ecologically sustainable development [3].

As a matter of fact, “... Scientific uncertainty and political realities dictate that governments should pursue their short-term interests rather than any long-term common purpose" [10], while it is agreed that "Sustainable development is development that meets the needs of the present without compromising the ability of future generations to meet their own needs" [26]. Nevertheless, despite the consensus in principle, there is a conflict in practice deriving from present circumstances of scientific uncertainty in relation with little action in practice. For instance, “... it is very difficult to pinpoint the exact source and precise effects of acid rain damage. The incidence and impact of acid rain vary according to a complex combination of meteorological, biological and geological conditions and the effects are cumulative. It was only after considerable political pressure from within the EC that the United Kingdom acceded to the desulphurisation programme, even though it managed to negotiate lower targets and a longer time-scale than some of its partners" [10].

Nevertheless, it is mostly accepted that sustainable development cannot be measured by means of single indicators, but requires a number of indicators (See, for instance, [1]). Moreover, both economic and environmental systems need at least a certain minimum achievement level in order to survive. It is also emphasized that, “... The plurality in views and fragmentation in institutional responses however is an indication that a satisfactory planning paradigm for sustainable development has not been found ..." [1]. There are also certain suspicions over the reliability of $\mathrm{CO}_{2}$ control strategies in the aftermath the Kyoto meeting [14].

Meanwhile, Munn points out that, human disturbances of the natural environment and large-scale environmental transformation characterized in terms of a number of environmental policy dilemmas could become major problems [20]. It is also pointed out that, “... The required levels (thresholds) regarding technical knowledge and/or public participation in environmental decision making differ widely from one environmental medium and country to the other..." [24].

On the other hand, the O.E.C.D. Council calls a work programme on environmental economics that would integrate environment and economic decision-making more systematically and effectively as a means of contributing to sustainable development [22]. Meanwhile, the World Development Report points out that the report focuses primarily on the welfare of developing countries and suggests the requirements for some measures in improving the environments of developing countries. As a conclusion, it is suggests that, “... There are policies that will allow developing countries to improve the efficiency with which their economics work while at the same time addressing many of the types of environmental damage... Developing countries need to give priority to the kinds of damage that most 
immediately threaten the quality of their citizens' lives" [27].

The major dilemma is pointed out: "The growing numbers of poor people living in more geographically focused poverty zones in the developing countries are not simply standing still, waiting to be touched by the magic hand of development. They are literally "losing ground" as their lands suffer more and more from the strains of too many people, inappropriate technology, or lack of "protective" infrastructural investment. Environmental destruction has become synonymous with poverty wherever poor people cluster together" [18].

In this way, the dilemma is the complexity of an environmental system covering urban and regional systems that calls for an integrated approach in decision-making processes in terms of land uses and environmental effects. Within this context regional and interregional cooperation is essential in promoting the sustainability of environmental quality.

In this context, interregionality may be of different scales ranging from smaller scales like catchment areas, lakes, rivers, bays, etc. extending to larger scales like seas shared by a number of countries within a truly international nature. To give examples, all settlements and/or municipalities located in the catchment area of a drinking water resource should act as one single body to protect the water quality and to keep it usable for its intended beneficial use. Likewise sophisticated methods of environmental pollution control in one community around a bay will most probably not suffice for keeping the bay at an acceptable level, if other communities do not do anything about it. In all cases of similar character, communities involved should handle the task within a systems approach and with a holistic viewpoint, and regional planning should be made accordingly.

It is argued that an interregional approach to capture the long-term effects on the organisation of the territory should take into account the environmental problems, beside the development within the framework of sustainable development. This approach should be related more to political issues based on cultural differences and on the aim of a bottom up approach to European integration, rather than to traditional regional policies. This may stimulate interregional, cross-cultural and transboundary cooperation [2] [12].

From the viewpoint of ecology, location and local participation, in other words for a bottom-up approach to European integration through interregional cooperation, the human ecocentric view seems the most appropriate viewpoint, since it is based on human relationships and place dependencies. It is pointed out that, studies by psychologists, anthropologists, environmental educators, and economists show that even knowledgeable, wellintentioned people frequently fail to adopt proenvironmental behaviors.

Meanwhile, it is suggested that, even though public participation is fundamental to the planning process, practitioners struggle with low levels of participation and with developing methods to broaden the public's voice in local decision making [25] [17]. In fact, without explicit environmental ethical premises, the sustainability debate is indeterminate.

The case studies are important in certain respects: First, they illustrate that sustainability can be an important organizing theme in planning a community's response to change; second, they show that through planning, concepts of sustainability evolve from individual to collective definitions; third they illustrate planning-based efforts to manage change [16].

In this article, two cases will be included in the second chapter in order to define 
interactions of land uses and environmental effects to examine those factors affecting the quality of urban life through a positivist approach. The third chapter will focus on measuring environmental performance through a combined method covering positivist and humanistic approaches together. The fourth chapter consists of concluding remarks.

\section{Some Examples in Terms of Interactions of Land Uses and Environmental Effects}

\subsection{The Impact of the Danube Basin on the Black Sea and the Marmara Sea}

An example of need for an international large-scale cooperation is the Black Sea, which is a actually an extension of the Mediterranean. It has been reported that the quality of the Black Sea has deteriorated greatly during the last decades [6] [5] [15].

A survey of "users of the Black Sea" shows that in addition to six riparian countries, there are "indirect users" of the Black Sea, through the meso-region of Danube basin which includes sixteen countries. These meso-regions covering the Danube basin as a region suggest a new strategic framework in the promotion of regional development. The Danube river, extending from Germany to Romania where it meets the Black Sea, is the most significant source of pollutants. It has been determined that more than half of the organic matter, nitrogen, phosphorous and suspended solids in the Black Sea flows from the Danube. Hence, the sustainability of water quality in the Black Sea is not only dependent on the efforts of the riparian countries but even more so on the countries located in the Danube basin.

The watershed of the Danube includes sixteen countries. The Black Sea hosts six riparian countries and is connected to the Mediterranean through the Bosphorus, Marmara Sea and the Dardanelles. Hence, pollution carried to the Black Sea by the Danube is not only a problem for the riparian countries of the Black Sea itself, but it may also be a potential risk to the Mediterranean Sea. The aim is to discuss the significance of indirect users along with direct users in terms of maintaining sustainability of regional environmental quality, and to point to the fact that it is a common responsibility and duty of all those involved, within the framework of an interregional/international cooperation to keep up with the sus-

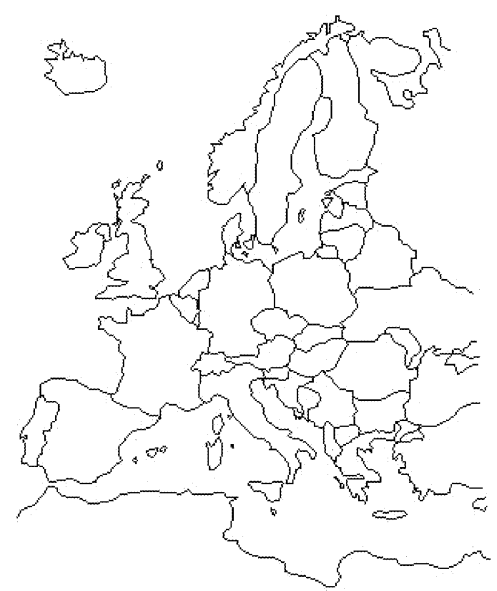

(a)

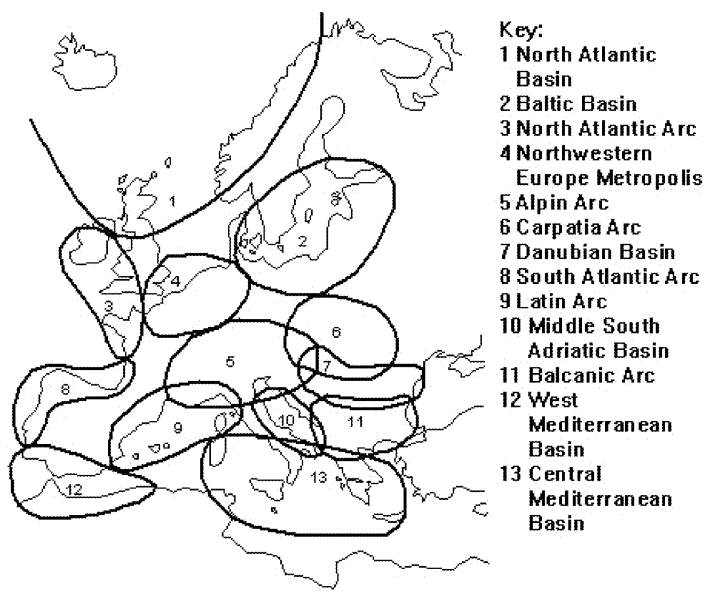

(b)

Figure 1. (a) The Europe of nation-states. (b) The Europe of regions. 
tainability of the region as a whole (Figure 1).

A comprehensive survey of the status of pollution in the Black Sea undertaken by the Global Environmental Facility (GEF) Black Sea Environmental Programme was completed in 1996 [15]. A survey of the documents reveals that significant pollutants in the Black Sea are organic matter characterized by Biochemical Oxygen Demand (BOD), or Total Organic Carbon (TOC), nutrients characterized by nitrogen and phosphorous, suspended solids, and oil [15]. The report also presented estimates of loads incoming to the Black Sea from various sources. Those estimates were used as basis to generate Table 1 .

Among these pollutants, nutrients characterized by total nitrogen and total phosphorous are of special concern since they are directly responsible for the world-wide problem of eutrophication. Simply stated, eutrophication is the excessive increase of primary production, due to excessive quantities of nitrogen and phosphorus, which are predominantly of anthropogenic origin, and which can come from anywhere within the catchment area of a water body. The process of eutrophication is also called ageing. In natural, balanced systems this is expected to occur in hundreds of years. However, due to uncontrolled discharge of nutrients of anthropogenic origin, this may be accelerated highly, and under those conditions, eutrophication may occur within several years [6].

Due to the growing threat of eutrophication, the European Union has issued a directive to control wastewater discharges, also introducing the new concept of "Sensitive Areas." Sensitive areas are defined as those areas that are sensitive to and under the possible threat of eutrophication. Special and more stringent standards are given for those areas that are to be declared as being sensitive. Among those standards, nitrogen and phosphorous have gained special attention. A survey of total nitrogen and total phosphorous in the Black Sea reveals that $58 \%$ of the total nitrogen and $68 \%$ of the total phosphorous load coming in is brought by Danube River. Total load here is defined as the sum of the loads coming in from domestic and industrial sources, and national and international rivers. The distribution of the origin of significant conventional pollutants is summarized in Table 1. The contribution of the Danube to the total in the Black Sea was calculated to be $48 \%$, in terms of oil pollution.

Table 1. The origin of significant conventional pollutants in the Black Sea (generated from the data in G.E.F., 1996) [6]

\begin{tabular}{|l|c|c|c|c|c|c|c|c|}
\hline \multicolumn{1}{|c|}{ Source } & $\begin{array}{c}\text { Total } \\
\text { Load } \\
\text { (t/y) }\end{array}$ & $\begin{array}{c}\text { Nitrogen } \\
\text { \% of } \\
\text { total }\end{array}$ & $\begin{array}{c}\text { Total } \\
\text { Load } \\
\text { (t/y) }\end{array}$ & $\begin{array}{c}\text { Phosphorous } \\
\% \text { of total }\end{array}$ & $\begin{array}{c}\text { Total } \\
\text { Load } \\
\text { (t/y) }\end{array}$ & $\begin{array}{c}\text { B.O.D. } \\
\% \text { of } \\
\text { total }\end{array}$ & $\begin{array}{c}\text { Total } \\
\text { Load } \\
\text { (t/y) }\end{array}$ & $\begin{array}{c}\text { S.S. } \\
\% \text { of } \\
\text { total }\end{array}$ \\
\hline $\begin{array}{l}\text { Domestic \& } \\
\text { Industrial }\end{array}$ & $1,476,968$ & 38 & 8,675 & 17 & 153,378 & 15 & 356,932 & 1 \\
\hline $\begin{array}{l}\text { International } \\
\text { Rivers }\end{array}$ & 229,181 & 58 & 39,888 & 78 & 844,573 & 82 & $48,803,520$ & 90 \\
\hline $\begin{array}{l}\text { National } \\
\text { Rivers }\end{array}$ & 14,715 & 4 & 2,713 & 5 & 37,684 & 3 & $4,816,511$ & 9 \\
\hline TOTAL & 391,864 & 100 & 51,276 & 100 & $1,035,635$ & 100 & $53,976,963$ & 100 \\
\hline Danube & 229,181 & 58 & 34,938 & 68 & 774,634 & 75 & $37,913,000$ & 70 \\
\hline Other Sources & 162,683 & 42 & 16,338 & 31 & 261,001 & 25 & $16,063,963$ & 30 \\
\hline
\end{tabular}


Table 2. Pollutant exchange between the Black Sea and the Marmara Sea through the Bosphorus (G.E.F., 1996) [6]

\begin{tabular}{|l|c|c|c|}
\hline & $\begin{array}{c}\text { Total Nitrogen } \\
\text { (tons/year) }\end{array}$ & $\begin{array}{c}\text { Total Phosphorous } \\
\text { (tons/year) }\end{array}$ & $\begin{array}{c}\text { Organic Matter as } \\
\text { T.O.C. (tons/year) }\end{array}$ \\
\hline Influx into the Marmara Sea & $1.2 \times 10^{4}$ & $1.9 \times 10^{5}$ & $1.52 \times 10^{6}$ \\
\hline Influx into the Black Sea & $1.0 \times 10^{4}$ & $0.6 \times 10^{5}$ & $0.35 \times 10^{6}$ \\
\hline
\end{tabular}

Pollutant exchange through the Bosphorus is also given in Table 2. An inspection of the table shows that there is a net flow of nitrogen, phosphorus and organic matter from the Black Sea into the Marmara Sea, which may pass over to the Mediterranean through the Dardanelles.

For environmental sustainability in the Black Sea, there is need for international and interregional cooperation in terms of controlling pollutants of primary significance, within a very large area, actually extending from Germany in the west, to Russian Federation and Georgia in the east. It should also be kept in mind that any kind of deterioration in the Black Sea may in time be a potential threat to the Mediterranean. Regional cooperation for the sustainability of environmental quality seems to be one of the major challenges mankind will have to face and well-balanced regional planning strategies are needed to accomplish this goal. The scale of "region" may vary from smaller scales like drinking water reservoir catchment areas to truly international scales, like the protection of the Black Sea.

\subsection{The Impact of the City of Istanbul on Watersheds}

The metropolitan area of Istanbul has certain problems like high population increase, inmigration, insufficient infrastructure, declining environmental quality and squatter settlements through a pseudo-urbanization process. In this stage, an inadequate infrastructure, specifically within the protection zones of catchment areas, further leads to the pollution of drinking water reservoirs.

Istanbul, with its population over 12 million and a high rate of population increase, is one of the largest metropolitan areas in the world. It has one of the world's highest rates of migration population settling in unplanned areas. Large numbers of migrating populations settling in unplanned areas with improper infrastructure at high densities lead to environmental deterioration. The case of Istanbul could be presented as an example, with the impact of unplanned settlements in the watersheds of drinking water reservoirs [9] [8]. Population increase and illegal housing with inadequate infrastructure, specifically within the protection zones of catchment areas, lead to pollution of drinking water reservoirs, especially as about $1 / 6$ of the Turkish population and almost $50 \%$ of Turkish industry is clustered around Istanbul and its vicinities (Figure 2).

When Figure 1 shows the population changes in the watersheds of Istanbul, Table 3 is a comparison of population characteristics and the watersheds of the drinking water reservoirs of Istanbul. The metropolis supplies almost all of its water demand from surface water reservoirs (Figure 3).

It is observed that the population growth was stable until 1980 after which a sharp began 
Table 3. Settlements in the watersheds of drinking water reservoirs of Istanbul [8]

\begin{tabular}{|c|c|c|c|c|c|c|c|c|}
\hline Watershed & $\begin{array}{c}\text { Water } \\
\text { Share } \\
(\%)\end{array}$ & $\begin{array}{l}\text { Protection } \\
\text { Zone }\end{array}$ & $\begin{array}{l}\text { Area } \\
\left(\mathrm{km}^{2}\right)\end{array}$ & $\%$ & $\begin{array}{c}\text { No. of } \\
\text { Settlements }\end{array}$ & Population & $\%$ & $\begin{array}{c}\text { Population } \\
\text { Density } \\
\text { Persons/ } \\
\mathrm{km}^{2}\end{array}$ \\
\hline \multirow{6}{*}{ Ömerli } & \multirow{6}{*}{36} & Absolute & 40 & 7 & 3 & 1,438 & 1 & 36 \\
\hline & & Short & 55 & 9 & 2 & 2,545 & 2 & 46 \\
\hline & & Medium & 63 & 10 & 4 & 963 & 1 & 15 \\
\hline & & Long & 440 & 74 & 17 & 145,964 & 96 & 332 \\
\hline & & Total & 598 & 100 & 26 & 150,910 & 100 & 252 \\
\hline & & & & & & & & Overall \\
\hline \multirow{6}{*}{ Terkos } & \multirow{6}{*}{23.3} & Absolute & 25 & 4 & 2 & 3,599 & 16 & 144 \\
\hline & & Short & 51 & 9 & 2 & 1,443 & 7 & 28 \\
\hline & & Medium & 62 & 11 & 3 & 927 & 4 & 15 \\
\hline & & Long & 449 & 76 & 14 & 15,926 & 73 & 35 \\
\hline & & Total & 587 & 100 & 19 & 21,895 & 100 & 37 \\
\hline & & & & & & & & Overall \\
\hline \multirow{6}{*}{ B. Cekmece } & \multirow{6}{*}{16.4} & Absolute & 19 & 3 & 3 & 2,697 & 4 & 142 \\
\hline & & Short & 34 & 6 & 1 & 12,240 & 16 & 360 \\
\hline & & Medium & 44 & 8 & 1 & 900 & 1 & 20 \\
\hline & & Long & 488 & 83 & 24 & 58,848 & 79 & 74 \\
\hline & & Total & 585 & 100 & 34 & 74,685 & 100 & 154 \\
\hline & & & & & & & & Overall \\
\hline \multirow{6}{*}{ Darlik } & \multirow{6}{*}{15.9} & Absolute & 11 & 9 & - & - & - & 0 \\
\hline & & Short & 17 & 9 & - & - & - & 0 \\
\hline & & Medium & 16 & 8 & - & - & - & 0 \\
\hline & & Long & 149 & 74 & 7 & 1,885 & 100 & 13 \\
\hline & & Total & 193 & 100 & 7 & 1,885 & 100 & 13 \\
\hline & & & & & & & & Overall \\
\hline \multirow{6}{*}{ Alibeyköy } & \multirow{6}{*}{5.9} & Absolute & 12 & 8 & 1 & 3,699 & 11 & 308 \\
\hline & & Short & 18 & 11 & - & - & - & 0 \\
\hline & & Medium & 20 & 13 & - & 31,007 & - & 0 \\
\hline & & Long & 107 & 68 & 5 & 34,706 & 89 & 293 \\
\hline & & Total & 157 & 100 & 6 & & 100 & 221 \\
\hline & & & & & & & & Overall \\
\hline \multirow{6}{*}{ Elmali } & \multirow{6}{*}{2.5} & Absolute & 10 & 14 & 1 & 4,693 & 4 & 469 \\
\hline & & Short & 12 & 16 & - & - & - & 0 \\
\hline & & Medium & 29 & 37 & 1 & 13,523 & 13 & 466 \\
\hline & & Long & 26 & 33 & 2 & 87,457 & 83 & 3,364 \\
\hline & & Total & 77 & 100 & 4 & 105,673 & 10 & 1,372 \\
\hline & & & & & & & & Overall \\
\hline
\end{tabular}

occurring in all watersheds in spite of certain regulations covering absolute, long-range, short-range protection zones in the area. On the other hand, Table 4 shows the most critical criteria in the metropolitan area as trophic criteria. "This compatible set of results points to the fact that the problem of eutrophication in Istanbul is the priority issue and that 

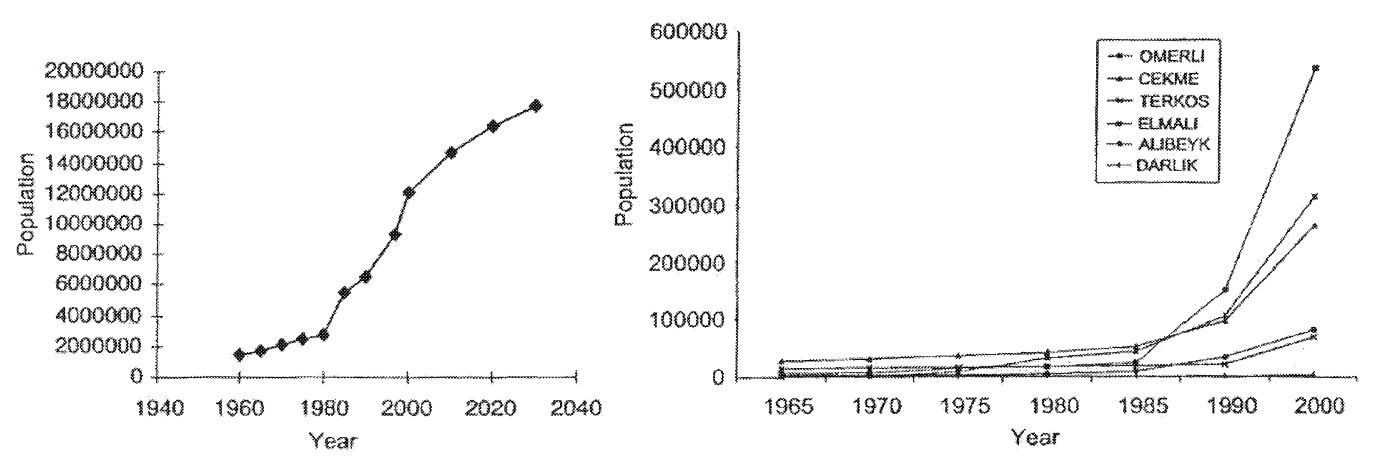

Figure 2. Population changes in Istanbul and its watersheds [8]

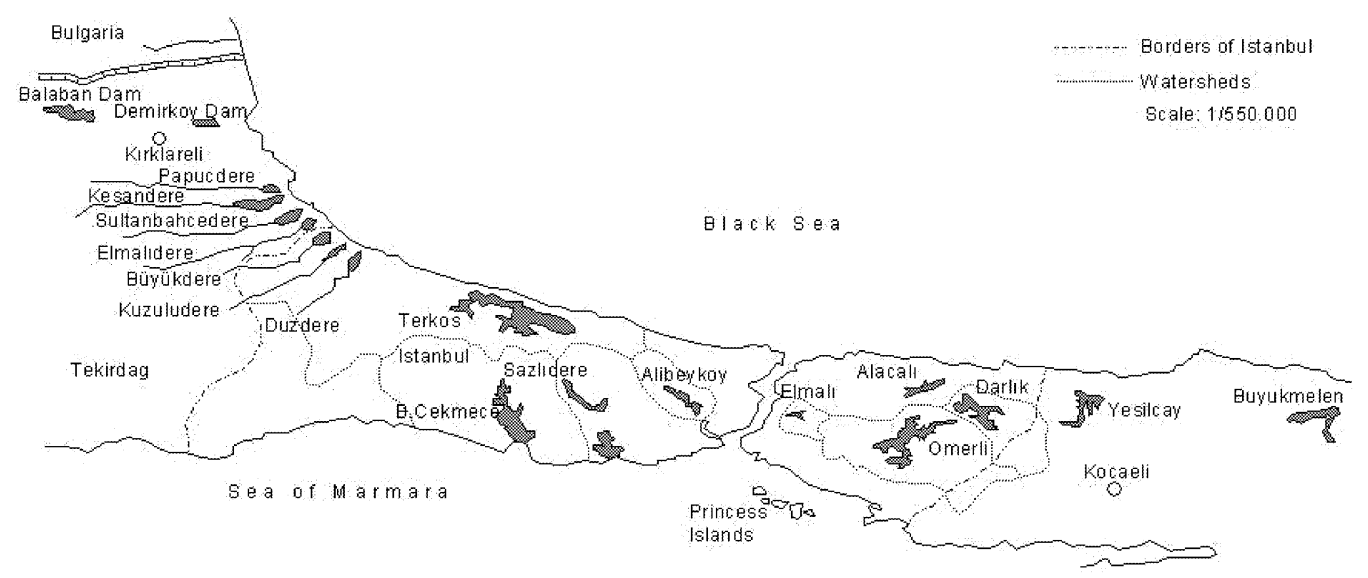

Figure 3. Present and future water resources of Istanbul [8]

Table 4. Classification of the drinking water reservoirs of Istanbul according to the Technical Standards [8]

\begin{tabular}{|c|c|c|c|c|}
\hline & $\begin{array}{l}\text { Hydrographic \& } \\
\text { Territorial Criteria }\end{array}$ & $\begin{array}{l}\text { Trophic } \\
\text { Criteria }\end{array}$ & $\begin{array}{c}\text { Salinityp, Special Criteria \& } \\
\text { Hygienically Relevant } \\
\text { Criteria }\end{array}$ & $\begin{array}{l}\text { Overall } \\
\text { Evaluation }\end{array}$ \\
\hline Ömerli & 2 & $3(2.9)^{*}$ & 2 & $2(2.3)$ \\
\hline Terkos & 2 & $3(2.5)$ & 3 & $2(2.7)$ \\
\hline B.Cekmece & 3 & $2(2.0)$ & 3 & $3(2.7)$ \\
\hline Darlik & 1 & $* *$ & 2 & $2(1.5)$ \\
\hline Alibeyköy & 3 & $3(2.5)$ & 2 & $3(2.7)$ \\
\hline Elmalı & 3 & $4(4.3)$ & 3 & $3(3.3)$ \\
\hline
\end{tabular}

* Numbers in parentheses indicate averages not rounded off

** Not reported due to very limited data

eutrophication control should actually start in the watershed, before pollutants reach the reservoirs." [9].

This observation deals with community perceptions of urban health risks : "Understanding how a community perceives health risks such as polluted water, inadequate drainage, or 
lack of garbage collection is essential to designing effective programs to address those problems. Individuals perceive risks to their health through a lens derived from their cultural, economic, societal, and educational backgrounds and respond accordingly." [28].

\section{Environmental Performance in a Developing Urban Area}

It is suggested that a comprehensive view of one aspect of quality of life means the quality of place or community life. A number of scholars have argued that objective indicators derived from statistics, are not the only measures of social conditions in the U.S. and that changes reflected by the statistics are often difficult to interpret. They have proposed that the meaning of these indicators may be interpreted with the help of subjective indicators reflecting quality of life or the psychological well-being of individuals [19]. On the other hand, a number of individuals operating at the interface of the social sciences and the environmental design professions have argued that understanding the objective characteristics of the physical environment and people's responses is important in enhancing the quality of a place.

Among a number of studies of well-being, satisfaction is viewed as more definable to researchers, as it implies a judgmental or cognitive experience, whereas happiness reflects a relatively short-term mood of elation or gaiety. Satisfaction is also considered a more plausible and realistic objective for policy makers than that of creating happiness (gaiety), as the researchers were interested in generating data that could potentially influence public policy. Finally, Campbell et al. felt that "satisfaction" was more appropriate to the goals of their study than "happiness" [11] [23]. Their intent was to measure and compare people's assessments of several domains of their lives as well as "life as a whole", and determine the degree to which each domain explained the quality of life experience. Domains considered were health, marriage, housing, family friendships, financial situation, leisure, and community or place of residence. With respect to domain satisfactions, Campbell and his colleagues suggested that domain satisfactions were a reflection of people's assessments and perceptions of domain attributes that in turn, were influenced by the objective attributes (characteristics) themselves. For example, perceptions of crowding in a dwelling were expected to be associated with an objective measure such as people per room or another measure of housing density.

In this framework, the "Urban Environmental Indicators" developed by O.E.C.D. could be a convenient example for co-operation of positivist and humanistic approaches in terms of objective and subjective indicators [7] [4] concerns, which are grouped under the main headings as housing, services and employment; ambient environment and nuisances; and social and cultural environment [21]. In fact, in this process, the choice of concerns is on the quality of man's urban environment. This approach, as an international co-operation effort, covers an effort to select information with respect to the planning concerns besides to concentrating on aspects of man's welfare and urban and environmental concerns from the viewpoint of the inhabitants. A certain number of indicators with their validity and measurability have been tested in a number of European cities. It is pointed out that, the emergence of a European-wide urban policy has given new impetus to the requirement for comparable indicators of the quality of life to monitor development and policy implementa- 
tion $[13]$.

A combination of a number of objective and subjective indicators is considered as explanatory variables in this context. In this way, the overall satisfaction measure is expressed by an equation of the form,

$$
S_{i}=a_{0}+\sum_{k=1}^{n} a_{k} Y_{k_{i}}
$$

where $Y_{k i}$ indicates value of indicator ' $k$ ' in the area ' $i$ '; $a_{k}$, weight of indicator ' $k$ '; $n$, number of indicators; $S_{i}$, satisfaction value of the area ' $i$, respectively [21]. It is also pointed out that a statistically significant equation of this form could be used to evaluate planning decisions for planning activities taking into account certain chances via a sort of input/output model, while the model is appropriate to evaluate cross-cultural differentiation in environmental performance for developed and developing areas. From the standpoint of ecologically sustainable urbanization, it should be useful to examine the overall satisfaction in an urban area with a model to be used to evaluate likely planning decisions. In this context, the performance of a metropolitan area could be measured by a number of independent variables, covering housing conditions, accessibility conditions, social and cultural parameters and environmental impact as a whole [7].

The data for the model depends on a field study for the Istanbul metropolitan area consisting of a 10 percent sampling for the streets and certain measures for the environmental conditions $^{(\mathrm{x})}$.

The basic form of the model is a stepwise multiple regression model and is shown below :

$$
\begin{gathered}
P E R=a Y 1^{b 1} \cdot E 1^{c} . E 2^{d} . E 3^{e} . E 4^{f} . C 1^{g} \cdot C 2^{h} . C 3^{i} \cdot C 4^{j} . A^{k} . T B^{1} . A D^{m} . K^{n} . S^{o} \\
\left(\log P E R=\log a+b_{1} \log Y 1+\ldots\right)
\end{gathered}
$$

where $P E R$ indicates performance, in other words satisfaction rate;

$Y_{1}$, Housing density;

$E_{1}$, Accessibility to shopping places;

$E_{2}$, Accessibility to schools ;

$E_{3}$, Accessibility to open spaces/green areas;

$E_{4}$, Accessibility to working places;

$C_{1}$, Dissolved oxygen rate;

$C_{2}, \mathrm{SO}_{2}$ rate in the air;

$C_{3}$, Waste disposal rate;

$C_{4}$, Noise level ;

$A$, Open space rate;

$T B$, Social integration rate;

$A D$, Land values,

$K$, Cultural activity rate;

$S$, Staying time in the location;

(x) This research has been supported by the Turkish Scientific and Technical Research Council. Members of the research team: G. Atalik, Director of the research; F. Bolen, C. Giritlioglu, Y. Unal, H. Ciraci, G. Erkut, P. Korca, F. Gezici, T. Baycan. 


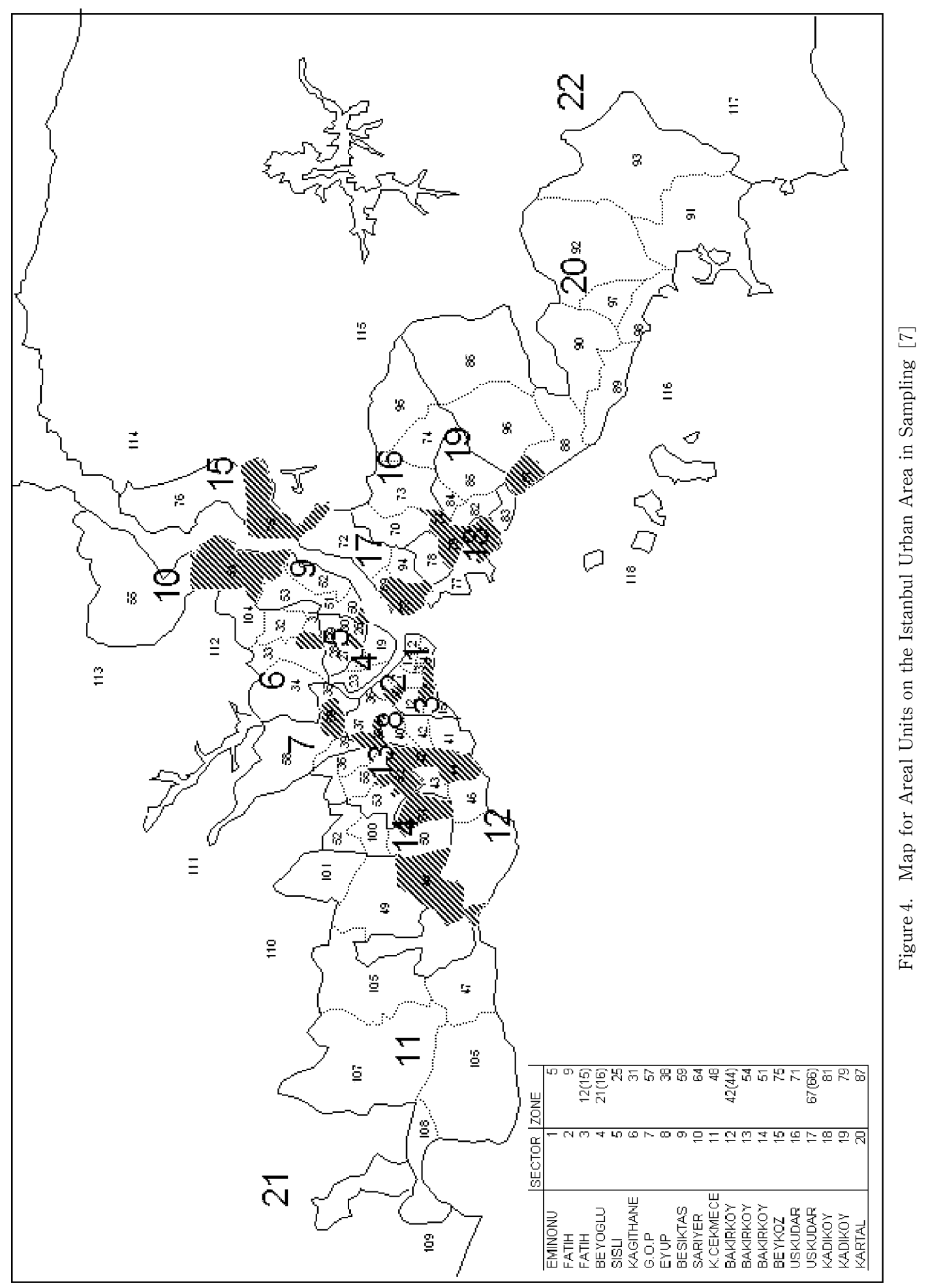




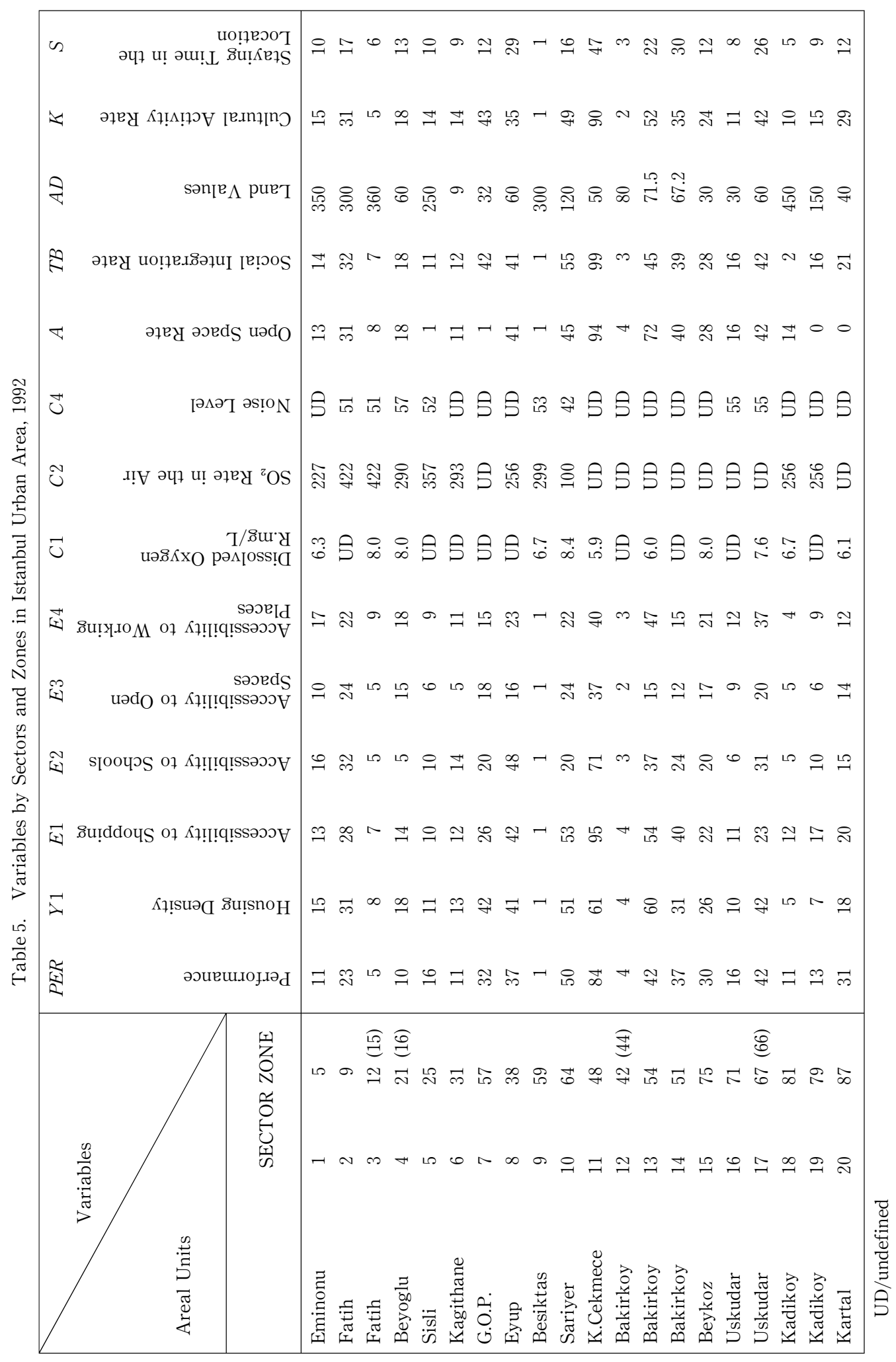




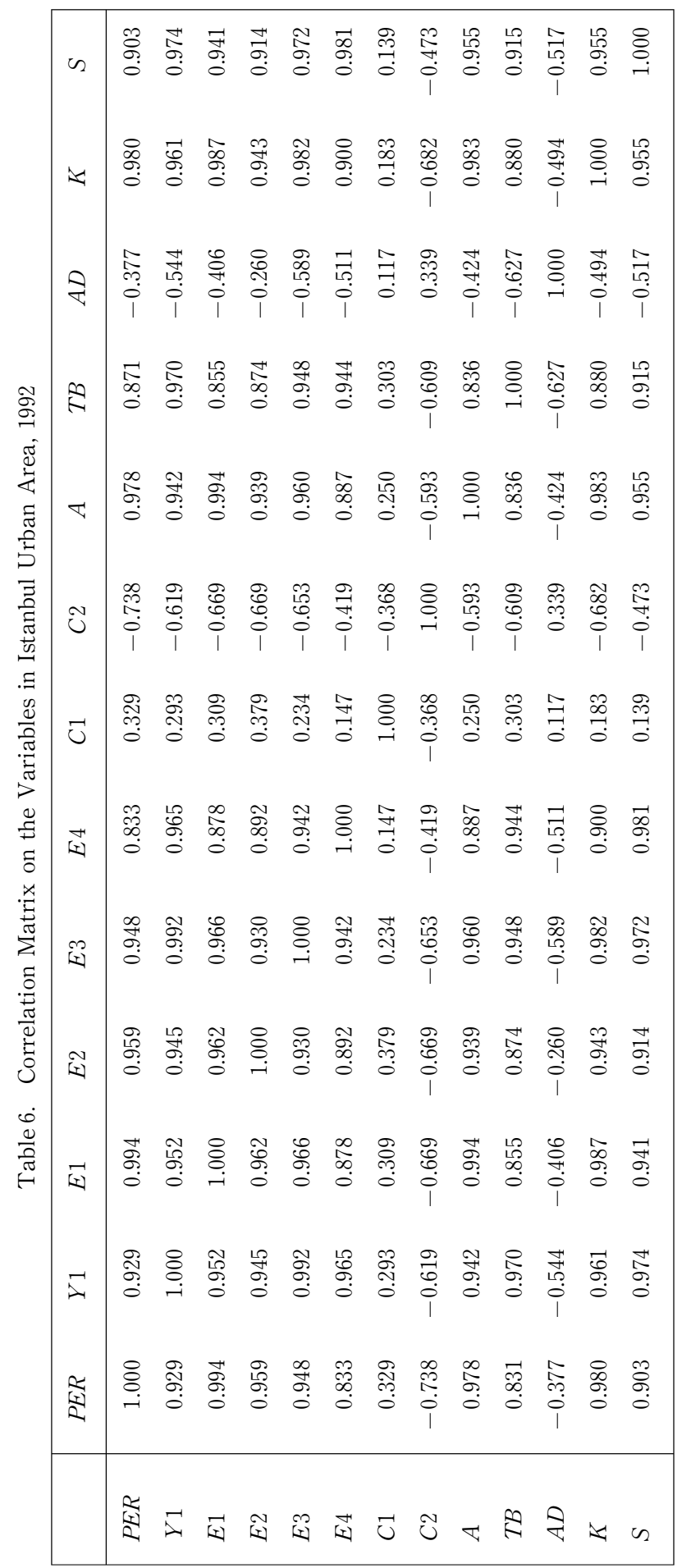


Table 7. Stepwise Multiple Regression Analysis on the Variables in Istanbul Urban Area, 1992

\begin{tabular}{|c|c|c|c|c|c|}
\hline \multicolumn{6}{|c|}{ Step Number 1 -Dependent Variable is PER } \\
\hline Multiple R & 0.99388 & & & & \\
\hline R Square & 0.98780 & & & & \\
\hline Adjusted R Square & 0.98475 & & & & \\
\hline \multirow{2}{*}{$\begin{array}{l}\text { Standard Error } \\
\text { Analysis of Variance }\end{array}$} & 0.06848 & & & & \\
\hline & DF & Sum of Squares & Mean Square & & \\
\hline Regression & 1 & 1.51891 & 1.51891 & & \\
\hline Residual & 4 & 0.01876 & 0.00469 & & \\
\hline $\mathrm{F}$ & 323.88579 & & & & \\
\hline \multirow{2}{*}{$\begin{array}{l}\text { Significant } \mathrm{F} \\
\text { Variable(s) in the E}\end{array}$} & 0.0001 & & & & \\
\hline & $\mathrm{B}$ & SE B & Beta & $\mathrm{T}$ & Sig. T \\
\hline $\mathrm{E} 1$ & 0.97807 & 0.05435 & 0.99388 & 17.997 & 0.0001 \\
\hline (Constant) & -0.4972 & 0.06038 & & -0.823 & 0.4565 \\
\hline \multicolumn{6}{|c|}{ Step Number 2-Dependent Variable is PER } \\
\hline Multiple R & 0.99879 & & & & \\
\hline R Square & 0.99758 & & & & \\
\hline Adjusted R Square & 0.99596 & & & & \\
\hline \multirow{3}{*}{$\begin{array}{l}\text { Standard Error } \\
\text { Analysis of Variance }\end{array}$} & 0.03525 & & & & \\
\hline & & & & & \\
\hline & DF & Sum of Squares & Mean Square & & \\
\hline Regression & 2 & 1.53394 & 0.76697 & & \\
\hline Residual & 3 & 0.00373 & 0.00124 & & \\
\hline $\mathrm{F}$ & 617.26830 & & & & \\
\hline \multirow{2}{*}{$\begin{array}{l}\text { Significant } \mathrm{F} \\
\text { Variable(s) in the E}\end{array}$} & 0.0001 & & & & \\
\hline & B & SE B & Beta & $\mathrm{T}$ & Sig. T \\
\hline E1 & 0.89055 & 0.03763 & 0.90494 & 23.668 & 0.0002 \\
\hline $\mathrm{C} 2$ & -0.35038 & 0.10074 & -0.13299 & -3.478 & 0.0401 \\
\hline (Constant) & 0.87315 & 0.26713 & & 3.268 & 0.0468 \\
\hline \multicolumn{6}{|c|}{ Step Number 3-Dependent Variable is PER } \\
\hline Multiple R & 0.99991 & & & & \\
\hline R Square & 0.99982 & & & & \\
\hline Adjusted R Square & 0.99954 & & & & \\
\hline \multirow{2}{*}{$\begin{array}{l}\text { Standard Error } \\
\text { Analysis of Varianc }\end{array}$} & 0.01187 & & & & \\
\hline & DF & Sum of Squares & Mean Square & & \\
\hline Regression & 3 & 1.53738 & 0.51246 & & \\
\hline Residual & 2 & 0.00028 & 0.00014 & & \\
\hline $\mathrm{F}$ & 3638.06854 & & & & \\
\hline \multirow{2}{*}{$\begin{array}{l}\text { Significant } \mathrm{F} \\
\text { Variable(s) in the } E\end{array}$} & 0.0003 & & & & \\
\hline & B & SE B & Beta & $\mathrm{T}$ & Sig. T \\
\hline E1 & 1.06253 & 0.03701 & 1.07971 & 28.710 & 0.0012 \\
\hline $\mathrm{C} 2$ & -0.35623 & 0.03394 & -0.13521 & -10.496 & 0.0090 \\
\hline E3 & -0.19396 & 0.03922 & -0.18251 & -4.946 & 0.385 \\
\hline (Constant) & 0.88281 & 0.08997 & & 9.812 & 0.0102 \\
\hline
\end{tabular}


while these independent variables were selected by Chi-squared tests on the data.

The method of areal studies covers collecting information from documentary sources and by means of interviews. Interviews based on stratified sampling as each of the different areal units (sector/zone) of the population is sampled by random methods where the respondents are householders. On the other hand, when the environmental variables as "dissolved oxygen", "SO2 rate in the air", "noise level" and "housing density as ground floor ratio", "land values", "staying time in the location" are due to actual measures, the other variables depend on the opinions of respondents. The variable "PER" (satisfaction rate), as the dependent variable, is taken into account by respondents' opinion on the overall environmental impact which is derived from the independent variables to be concerned (Table 5, Table 6, Table 7).

As a result in the multiple regression model, determination coefficient depending on $\mathrm{SO}_{2}$ rate in the air and accessibility rate to open spaces/green areas indicates a higher level explained variation rate $\left(R^{2}=0.99\right)$. Meanwhile, the relationship between performance and the rate of dissolved oxygen seems not considerable $\left(r_{P E R . C 1}=0.329\right) . \quad \mathrm{SO}_{2}$ rate in the air $\left(\mathrm{C}_{2}\right)$ shows negative relationships with the majority of the variables except land values. $\mathrm{C}_{1}$ (dissolved oxygen rate) and $\mathrm{C}_{2}\left(\mathrm{SO}_{2}\right.$ rate in the air) indicate negative or weakly positive figures for the relationships with social and cultural variables. The relationship between dissolved oxygen rate and open space rate indicates the figure $r_{C 1 . A}=0.250$, while the relationship between $\mathrm{SO}_{2}$ in the air and open space rate gives the figure $r_{C 2 . A}=-0.593$ correspondingly.

Conclusively, it is inevitable that these relationships and the corresponding parameters could be evaluated as indications of cross-cultural differentiations among the countries, if performance in a certain urban area could be measured by satisfaction rate of the inhabitants.

\section{Concluding Remarks}

- It is known that, when the epistemology for positivist approaches require some experience be firmly established as verifiable evidence on which all agree on the one hand, epistemology for humanistic approaches requires some knowledge obtained subjectively in a world of meanings created by individuals emphasizing individuality and subjectivity rather than replicability and truth. A simple evaluation of these approaches together could give us a basic understanding for determinants of ecologically sustainable development and the factors affecting the quality of urban life.

- In this context, interregionality may be of different scales ranging from smaller scales like catchment areas, lakes, rivers, bays, etc. extending to larger scales like seas shared by a number of countries within a truly international nature. In all cases similar in character, the communities involved should handle the task within a systems approach and with a holistic viewpoint, and regional planning should be carried out accordingly. From the viewpoint of ecology, location and local participation, in other words for a bottom-up approach to European integration through interregional cooperation, the human ecocentric view seems the most appropriate viewpoint, since it is based on the human relationships and place dependencies. In fact, without explicit environmental ethical premises, the 
sustainability debate is indeterminate.

- A survey of "users of the Black Sea" shows that in addition to six riparian countries, there are "indirect users" of the Black Sea, through the meso-region of Danubian basin that includes sixteen countries. The aim is to discuss the significance of indirect users in terms of maintaining sustainability of regional environmental quality and to point at the fact that it is a common responsibility and duty of all those involved, within the framework of an interregional/international cooperation to keep up with the sustainability of the region as a whole. Regional cooperation for the sustainability of environmental quality seems to be one of the major challenges mankind will have to face and well-balanced regional planning strategies are required to accomplish this goal. The scale of "region" may vary from smaller scales like drinking water reservoir catchment areas to truly international scales, like the protection of the Black Sea.

- The metropolitan area of Istanbul has certain problems, like a high population increase, inmigration, insufficient infrastructure, squatter settlements and declining environmental quality through a pseudo-urbanization process. In this stage, an inadequate infrastructure, specifically within the protection zones of catchment areas, further lead to pollution of drinking water reservoirs. This observation deals with the community perceptions of urban health risks.

- Understanding how a community perceives health risks such as polluted water, inadequate drainage, or lack of garbage collection is essential to the designing of effective programs to address those problems. Individuals perceive risks to their health through a lens derived from their cultural, economic, societal, and educational backgrounds and respond accordingly.

- Among a number of studies of well being, "satisfaction" is viewed as more definable to researchers, and implies a judgmental or cognitive experience whereas "happiness" reflects a relatively short-term mood of elation or gaiety. Satisfaction is also considered a more plausible and realistic objective for policy makers than that of creating happiness, as the researchers are interested in generating data that could potentially influence public policy.

- From the standpoint of ecologically sustainable urbanization, an examination of the overall satisfaction in a mega-city like Istanbul with a model to be used to evaluate likely planning decisions seems most appropriate. In this context, the performance of a metropolitan area may be measured by a number of independent variables, including those of housing conditions, accessibility conditions, social and cultural parameters and environmental impact as a whole.

- Among a number of approaches in human geography, positivist and humanistic approaches together seem particularly meaningful in respect to regional differentiation in efforts leading to ecologically sustainable development. In this context, transboundary determinants on regional basis seem two-sided; in other words, both positivist and humanistic expressions of the relevant variables are verifiable.

- In fact, a number of arguments from actual experience in developed areas and indications of cross-cultural differentiation in a developing area by performance as a whole, in comparison with the other European patterns, prove certain limitations in implementing environmental policies and international commitments for helping the course towards 
sustainable future for European Regions. Since the choice of a particular method for a specific project assessment depends on the cultural context, beside political and administrative structure, public participation becomes fundamental in playing even more significant roles in environmental decision-making.

\section{References}

[1] Archibugi, F., Nijkamp, P. and Soeteman, F.J., "The Challenge of Sustainable Development" in F. Archibugi and P. Nijkamp (eds) Economy and Ecology : Towards Sustainable Development, Dordrecth: Kluwer Academic Publishers, 1989, pp. 1-12.

[2 ] Atalik, G., "European Integration and Regional Development" in "Studies in Honour of Professor Nicholas Konsolas", Panteion University of Social and Political Sciences, Athens, 2005, pp. 445-464.

[3] Atalik, G. and Levent, T.B., "An Interpretation of the Impact of Regional Science in Terms of Philosophy of Science", The Journal of RSAI 77, 1998, 4: 1-18.

[4] Atalik, G. and Türksever, N.E., "Possibilities and Limitations for the Measurement of the Quality of Life in Urban Areas with respect to Regional Variations", 39 th ERSA Congress, CD-ROM, 1999, Dublin.

[5] Atalik, G., "Environment and Development/ The Mediterranean and the Turkish Case" in Mediterranean Multiregionality ed. G. Bianchi, AISREI, Serie Science Regionali 3, 1997, pp. 29-47, Toscana Firenze.

[6] Atalik, G., Baykal, B.B. and Levent, T.B., "Some Cross-Cultural Determinants of Environmental Sustainability in the Framework of Interregional Cooperation in Europe: The Impact of the Danubian Basin through the Black Sea on the Sustainability of the Mediterranean", $37^{\text {th }}$ ERSA Congress, $C D-R O M$, 1997, University of Rome "Tor Vergata" Rome.

[ 7 ] Atalik, G., Ciraci, H. and Baycan, T., "Some Remarks on the Transboundary Environmental Determinants for European Regions: Cross-Cultural Differentiation in Environmental Performance" $33^{\text {rd }}$ ERSA Congress, 1993, Moscow.

[ 8 ] Baykal, B.B., Tanik, A. and Gonenc M., "The Impact of Watershed Land Use on Maintaining Acceptable Quality Influents for Water Treatment Plants" Journal of Water Supply: Research and Technology-AQUA, 52.8., 2003, pp. 587-595.

[9 ] Baykal, B.B., Tanik, A. and Samsunlu, A., "Rapid and Illegal Settlements in a Mega City and Its Impact on Drinking Water Reservoirs" in O. Ural, et al., Housing Construction, XXX IAHS World Congress on Housing, vol. 2, 2002.

[10] Blowers, A., "Sustainable Urban Development: The Political Prospects" in M.J. Breheny (ed.), Sustainable Development and Urban Form, Pion Limited, London, 1992, pp. 24-38.

[11] Campbell, A., Converse, P. and Rodgers, W., The Quality of American Life: Perceptions, Evaluations and Satisfactions, 1976, New York: Russel Sage Foundation.

[12] Cappellin, R., "Interregional Cooperation in Europe: An Introduction" in R. Cappellin, P.W.J. Batey (eds) Regional Networks, Border Regions and European Integration, Pion Limited, London, 1993, pp. 1-20.

[13] Craglia, M., Leontidou, L., Nuvolati, G. and Schweikart, J., "Towards the Development of Quality of Life Indicators in the 'digital' city", Environment and Planning B : Planning and Design, vol. 31, 2004, pp. 51-64.

[14] Ekinci, E., Incecik, S., " $\mathrm{CO}_{2}$ Control Strategies Aftermath the Kyoto Meeting and Turkey" in G. Kocasoy (ed) The Kriton Curi International Symposium on Environmental Management in the Mediterranean Region, Proceedings: vol. 2, 1998, pp. 893-898.

[15] GEF (The Global Environment Facility)/Black Sea Environmental Programme, 1996, Black Sea Transboundary Diagnostic Analysis. 
[16] Hanna, K.S., "Planning for Sustainability”, Journal of the American Planning Association, vol. 71, no. 1, 2005, pp. 17-40.

[17] Laurian, L., "Public Participation in Environmental Decision Making", Journal of the American Planning Association, vol. 70, no. 1, 2004, pp. 53-65.

[18] Leonard, H.J., Environment and the Poor: Development Strategies for a Common Agenda, 1989, Washington D.C., Overseas Development Council.

[19] Marans, R.W., “The Policy and Research Benefits of Quality of Urban Life Studies”, in N.Z. Gülersoy, et al. (eds) Quality of Urban Life : Policy Versus Practice, Istanbul Tech. Univ., 2003, pp. $33-47$.

[20] Munn, R.E., Towards Sustainable Development: An Environmental Perspective in F. Archibugi and P. Nijkamp (eds), Economy and Ecology: Towards Sustainable Development, Kluwer Academic Publishers, Derdrecht, 1989, pp. 49-72.

[21] OECD, Urban Environmental Indicators, 1978, Paris.

[22] OECD, Environmental Indicators, 1991, Paris.

[23] Potter, J.J., Environmental Satisfaction: Quality is in the Eye of the Beholder", in N. Gülersoy, et al. (eds) Quality of Urban Life: Policy Versus Practice, Istanbul Tech. Univ., 2003, pp. 107-122.

[24] Simonis, U., Ecological Modernisation of Industrial Society-Three Strategic Elements, in F. Archibugi and P. Nijkamp (eds) Economy and Ecology: Towards Sustainable Development, Kluwer Academic Publishers, Dordrecht, 1989, pp. 119-137.

[25] Thompson, R.H., "Overcoming Barriers to Ecologically Sensitive Land Management", Journal of Planning Education and Research, vol. 24, 2004, pp. 141-153.

[26] WCED, Our Common Future (The Brundtland Report), Oxford Univ. Pres, 1987, Oxford.

[27] World Bank, Development and the Environment: World Development Indicators, World Development Report, Oxford Univ. Press, 1992, Oxford.

[28] World Resources Institute, World Resources: A Guide to the Global Environment/1996/97, Oxford Univ. Press, 1996, Oxford. 